\title{
Cadeias globais de valor e desindustrialização: as transformações na estrutura produtiva brasileira em perspectiva comparada à indústria internacional* $^{*}$
}

\author{
Global Value Chains and Deindustrialization: Brazilian Productive Structure \\ Transformations Compared to International Industry
}

\begin{abstract}
Guilherme Nascimento Gomes e Antônio Carlos Diegues ${ }^{* *}$
\end{abstract}
\begin{abstract}
Resumo: Este trabalho analisa as transformações na estrutura produtiva brasileira entre 2000 e 2014 em perspectiva comparada a Estados Unidos, Alemanha, Japão, China e México. Busca-se contribuir para a literatura ao se avaliar, por meio das dimensões produtiva e tecnológica, o grau de aproximação (catching up) ou distanciamento (falling behind) da indústria brasileira face à fronteira internacional. Para tal, parte-se da hipótese de que a constituição de Redes Globais de Produção esteve associada a um fenômeno razoavelmente generalizado de transformações na forma de estruturação das indústrias domésticas em direção a um menor adensamento, inclusive no caso brasileiro, com conseguintes impactos em suas possibilidades de desenvolvimento produtivo. Os principais resultados mostram que há um distanciamento da economia brasileira em relação à fronteira internacional nas dimensões produtiva e tecnológica. Mostram também que há um aumento no gap de produtividade (falling behind) entre as estruturas produtivas de quase todos os países selecionados em relação à indústria estadunidense, com exceção da China.
\end{abstract}

Palavras-chave: Desindustrialização; Redes Globais de Produção; Catching up; Falling Behind

\begin{abstract}
This paper analyzes Brazilian productive structure transformations, compared to the United States, Germany, Japan, China and Mexico, between 1995 and 2014. It contributes to the literature measuring the degree of productive and technological ap.p.roaching (catching up) or distancing (falling behind) of the Brazilian industry compared to the international benchmarking. The hypothesis is that constitution of Global Production Networks has led to reasonably widespread transformations in the form of structuring domestic industries towards lesser density, including in Brazilian case, with consequent impacts on their possibilities for productive development. The main results show a distancing of the Brazilian economy in relation to the international
\end{abstract}

\footnotetext{
* Submissão: 16/09/2019 | Aprovação: 05/07/2020 | DOI: 10.5380/re.v42i78.69219

** Respectivamente: (1) Doutorando em Política Científica e Tecnológica, Universidade Estadual de Campinas (Unicamp), Brasil | E-mail: guingomes@gmail.com | ORCID: 0000-0002-4701-7091 | (2) Professor do Instituto de Economia, Núcleo de Economia Industrial e da Tecnologia (NEIT), Universidade Estadual de Campinas (Unicamp), Brasil | E-mail: diegues@unicamp.br | ORCID: 0000-0002-4124-666X
} 
frontier in the productive and technological dimensions. It has also been shown that there is an increase in the productivity gap between the productive structures of almost all the selected countries in relation to the American industry, except China.

Keywords: Deindustrialization; Global Production Networks; Catching up; Falling Behind

JEL: L060; O54; O14; L16 


\section{Introdução}

As transformações na estrutura produtiva mundial a partir da consolidação do paradigma tecno-econômico da microeletrônica (Dosi, 1982; Perez, 2004) tem motivado o debate acerca da reorganização da indústria global e sobre sua dinâmica competitiva. A partir desse cenário, observa-se o deslocamento da estrutura organizacional da empresa Chandleriana para o da "empresa em rede", cujas unidades industriais estão envolvidas em novos padrões de produção modularizados em escala global, os quais condicionam a dispersão geográfica das atividades integradas (Gereffi, 1999; Ernst; Kim, 2002).

A globalização alterou a dinâmica competitiva industrial das nações, uma vez que se observam mudanças no padrão de comércio internacional a partir de um aumento expressivo das importações dos países desenvolvidos (principalmente de bens intermediários), fenômeno este derivado da tendência de deslocamento da produção para as novas economias industrializadas com o recrudescimento da concorrência asiática. Esse fato é constatado por meio das mudanças organizacionais que transformaram e condicionaram o novo modelo de organização industrial. O conceito da empresa moderna capitalista de caráter multidivisional dá lugar a um novo conceito associado à modularização da produção integrada em redes globais ${ }^{1}$.

Nesse sentido, alguns países têm passado por mudanças nos padrões estruturais produtivos com perdas na participação do valor adicionado (VA) e do emprego industrial, principalmente em setores com alta produtividade onde os processos produtivos são mais suscetíveis à fragmentação em rede, como os do complexo eletrônico. Assim, a perda de representatividade destes setores tem ampliado as lacunas dos países alvos desta mudança estrutural regressiva em relação à fronteira tecnológica internacional.

No que tange ao debate brasileiro, as transformações nas estruturas produtivas, ocorridas nos últimos anos, têm levado a economia a um baixo crescimento principalmente devido à perda da importância relativa do setor manufatureiro. De maneira geral, este artigo compreende que a integração importadora brasileira nas redes globais apresenta um caráter estrutural, pois emerge como resultado da combinação entre o esgotamento do modelo de

\footnotetext{
${ }^{1}$ As expressões "Redes Globais de Produção" e "Cadeias Globais de Valor" utilizadas nesse artigo são sinônimas e possuem sentidos intercambiáveis.
} 
industrialização por substituição de importações em paralelo à reorganização empresarial e dos sistemas produtivos globais. Integração esta que ocorre em um cenário de deslocamento relativo do parque produtivo global em direção ao leste e sudeste asiáticos, fenômeno este denominado por Sarti e Hitauka (2017) de “chinalização industrial”.

Nesse sentido, observa-se que há um debate recente na literatura acerca das possibilidades de reshoring em direção aos Estados Unidos e aos demais países centrais de uma parcela das atividades manufatureiras deslocadas em direção à Ásia a partir da formação das cadeias globais de valor. Esse debate busca avaliar como a emergência das tecnologias características do que tem se denominado de Indústria 4.0 poderia contribuir para as transformações na dinâmica de criação de assimetrias competitivas em diversos setores que foram externalizados em busca de menores custos de produção (para uma análise do impacto destas tecnologias na reconfiguração das redes globais, ver Diegues e Roselino, 2019). Apesar da relevância do tema, dado o caráter bastante incipiente da gestação da Indústria 4.0 e a natureza prospectiva de seus possíveis impactos futuros, este trabalho procura compreender a relação entre o movimento já consolidado de formação destas cadeias e os impactos já mensurados na indústria dos países selecionados.

Neste contexto, o objetivo geral do trabalho é analisar as mudanças na estrutura produtiva brasileira no período entre 2000 e 2014 em perspectiva comparada às estruturas produtivas dos Estados Unidos, Alemanha, Japão, China e México. Assim, busca-se analisar as mudanças estruturais ocorridas em países selecionados pelas óticas do VA e do emprego industrial, além de identificar seus impactos sobre a produtividade. Adicionalmente, o trabalho busca contribuir para a literatura ao mensurar a evolução do grau de aproximação (catching up) ou de distanciamento (falling behind) da produtividade da indústria brasileira da fronteira internacional.

Por sua vez, a fronteira tecnológica internacional é definida neste trabalho a partir da comparação entre os níveis de produtividade dos países com maior representação no VA manufatureiro internacional. Deste modo, empiricamente, justifica-se a escolha da economia dos EUA. Tal fato não significa afirmar que a indústria de tal país seja necessariamente líder em termos de avanço tecnológico, diferencial competitivo ou que concentre as principais marcas globais em todos os setores e atividades industriais. Uma vez que o trabalho se propõe a realizar uma 
análise com níveis de agregação tradicionais na literatura internacional - setorial, a dois dígitos -, observa-se que o nível de produtividade da indústria estadunidense, a partir deste recorte, é o mais elevado entre todos os principais parques manufatureiros nacionais. Ainda, tal fato não significa, contudo, que essa liderança seja incompatível com a presença de empresas industriais de outros países com posição de destaque em diversos segmentos. Dentre tais exemplos pode-se citar a sólida presença de empresas japonesas em segmentos do complexo eletrônico e o destaque do complexo automobilístico alemão. Entretanto, apesar da relevância destas posições, a produtividade agregada estadunidense ainda é substancialmente maior que a dos respectivos países.

Assim, a ideia é qualificar o debate da literatura ao analisar tanto as transformações domésticas quanto internacionais em perspectiva dinâmica, uma vez que a fronteira internacional (entendida como a indústria com maior patamar de produtividade no período entre os países analisados, ou seja, a dos EUA) também é afetada pelos movimentos que assolam a indústria global.

Justificam-se as escolhas das outras configurações produtivas nacionais: a Alemanha como principal economia da União Europeia, o Japão sendo importante país desenvolvido da região asiática, a China que surge como principal país na indústria manufatureira global e o México devido ao fato de ser a segunda economia latino-americana, e apresentar um parque produtivo diversificado que sofreu transformações qualitativamente significativas a partir do aprofundamento da complementaridade produtiva com a indústria dos EUA nas últimas duas décadas. O método de analisar as transformações na indústria global de modo comparado ainda permite examinar o processo de regionalização das Cadeias Globais de Valor (CGV). Isso porque, a rigor, as cadeias de suprimentos tendem a ser fundamentalmente regionalizadas, fato este que está na origem das configurações que a literatura convencionou denominar de Factory Asia, Factory North America e Factory Europe. Nesse sentido, a geografia importa na escolha para a integração das redes, até mesmo para o desenho e aplicações de políticas (Baldwin, 2011; Baldwin; Lopez-Gonzalez, 2014).

Este trabalho se divide em três seções, além desta introdução e da conclusão. A segunda seção recupera brevemente os aspectos teóricos da literatura sobre a nova configuração produtiva global que tende a dispersar geograficamente a produção manufatureira com intensa concentração espacial em regiões de baixos 
custos produtivos, principalmente no leste e sudeste asiático. A seção seguinte versa sobre os aspectos das mudanças na estrutura produtiva global e os impactos de reorganização das cadeias de produção. Já na terceira seção, analisa-se o posicionamento da indústria manufatureira brasileira face à fronteira internacional.

\section{Desindustrialização no contexto das cadeias regionais e globais de produção}

As transformações ocorridas na estrutura produtiva mundial levaram ao redirecionamento da produção às redes regionais e globais de valor. Observa-se um processo de fragmentação da indústria manufatureira com deslocamento da produção de países industrializados para regiões de baixo custo, com o sucesso da integração às redes principalmente de países do leste e sudeste asiático.

Esse processo apoia-se na emergência da empresa em rede, fenômeno viabilizado também pela consolidação do paradigma tecno-econômico baseado na microeletrônica e facilitado por meio das tecnologias da informação e comunicação (TICs) (Sturgeon, 2002; Gereffi et al., 2005). A principal função das redes é fornecer acesso rápido e de baixo custo a recursos, capacidades e conhecimentos que são complementares às competências essenciais da empresa (Ernst; Kim, 2002).

Essas transformações reconfiguraram as estratégias globais de produção, gestão e inovação empresarial, levando a uma nova divisão internacional do trabalho com especialização de países em desenvolvimento em atividades manufatureiras e de montagem, ao passo que países desenvolvidos especializaramse em atividades de pesquisa e desenvolvimento (P\&D), design e inovação (DE Backer et al., 2015). Portanto, as atividades manufatureiras e de montagem estão cada vez mais dispersas e concentradas na periferia capitalista, ligadas globalmente por meio de redes. Em contrapartida, conforme lembram Hiratuka \& Sarti (2017), ainda se observa uma grande concentração dos resultados dos esforços inovativos nos países desenvolvidos, os quais foram os detentores de 94,58\% das patentes depositadas no Escritório Europeu de Patentes no período 2000-2009.

Vale lembrar que o processo de fragmentação produtiva manufatureira também se estende para setores de serviços. Nesse contexto, também vale lembrar que o conteúdo das exportações globais passa a ter uma maior participação das 
atividades de serviços em detrimento daquelas estritamente produtivas. Fruto deste movimento, Lauz e Maurer (2015) afirmam que em média os serviços representam um terço dos insumos nas exportações de manufaturados de países centrais e $26 \%$ nas exportações de países em desenvolvimento - no bojo do processo denominado de servicificação.

O processo de mudança estrutural em países industrializados, no qual o setor manufatureiro perde importância para o setor de serviços é então potencializado pela maior integração dessas economias nas CGV. Ou seja, há um aumento da importância dos serviços industriais em países centrais e em desenvolvimento como resultado do crescente processo de terceirização e deslocalização global das atividades produtivas.

Essa mudança no eixo de produção global é o ponto central para o que Gereffi (1999) denomina de "milagre asiático", com especial destaque para o processo de consolidação da indústria chinesa como a "workshop of the world", em um contexto de consolidação daquela que é uma das principais cadeias regionais de produção: a Factory Asia. A título de ilustração vale destacar o aumento de participação da economia chinesa no VA manufatureiro mundial de 10\% em 2005 para 26\% em 2016 segundo dados da UNIDO (ao passo que a evolução destes percentuais para os EUA foi de $22 \%$ para 18\%). Nesta configuração, destaca-se a proeminência crescente da indústria chinesa tanto nas dimensões produtiva e tecnológica (De Backer et al., 2015) quanto na presença crescente de grandes transnacionais e marcas de origem chinesa nos principais mercados mundiais (fenômeno este que avança substancialmente a partir de meados da segunda década dos anos 2000, segundo Nolan (2012)). Vale destacar ainda que a tendência de queda de participação no total do VA manufatureiro global também se estende à Alemanha e Japão. Segundo Morceiro e Tessarin (2019), entre 1990 e 2017, estes países tiveram sua participação neste total reduzida em $35,8 \%$ e $39 \%$, respectivamente.

\footnotetext{
2 Vale lembrar, entretanto, que o processo de desverticalização empresarial característico da empresa em rede é resultado das transformações do modelo de organização principalmente da grande empresa estadunidense e europeia, se estendendo em dimensões muito menores às configurações empresariais asiáticas típicas de cada nação como os keiretsus, os chaebols e os grandes conglomerados chineses. Neste sentido, a relação entre o milagre asiático e a formação da empresa em rede reside no fato de que o deslocamento das atividades produtivas da grande empresa estadunidense e europeia para os conglomerados produtivos é um elemento central para o dinamismo na região e para seu conseguinte processo de transformação estrutural.
} 
No que se refere especificamente às cadeias - em suas dimensões global e regional - Los, Timmer e De Vries (2015) mostram uma tendência geral de aumento da participação do VA estrangeiro no total da produção doméstica entre 1995 e 2008. Para o caso da Alemanha, esse total aumenta de 18,1\% para 30,1\%. A participação da cadeia regional europeia no total é de 14,4 pontos percentuais (p.p.) deste total. Nos EUA, observa-se uma representatividade relativamente pequena da cadeia regional do $\mathrm{Nafta}$ (4,2 p.p. de um total de 20,2\% da participação do VA estrangeiro na produção doméstica). Para o Japão, o mesmo fenômeno se verifica - baixa participação da cadeia regional asiática. Esses números são de 2,9 p.p. no total de 19,3\%. Em dois casos emblemáticos, os autores analisam a evolução da participação do VA estrangeiro na produção doméstica dos setores de equipamentos de transporte e de máquinas elétricas para Alemanha e EUA respectivamente. No primeiro país a participação do VA estrangeiro aumentou $61 \%$ entre 1995 e 2008 (de 21,1\% para 34\%, sendo que sua distribuição em 2008 era de $54,70 \%$ originário da cadeia europeia e $12,65 \%$ da cadeia asiática). No caso americano, o crescimento do VA estrangeiro foi de 45,5\% no mesmo período. Já a distribuição do VA entre cadeias regionais, em 2008, era bem mais homogênea que o caso alemão, com a cadeia asiática representando $29 \%$ do total e a cadeia do Nafta representando $21,6 \%$.

A partir da reorganização produtiva global associada ao surgimento da empresa em rede, à consolidação de cadeias regionais e ao acirramento da concorrência internacional principalmente devido ao processo de "chinalização industrial" (Sarti; Hiratuka, 2017), destaca-se a retomada da relevância na literatura acerca da desindustrialização e da centralidade da indústria para o desenvolvimento econômico. Tal fato se materializa, segundo Chang e Andreoni (2016), no reconhecimento crescente do valor da política industrial entre países desenvolvidos e emergentes, pós-crise financeira de 2008, como instrumento para contornar os desafios (baixo dinamismo, aumento da concentração de renda, alto desemprego) impostos pela desindustrialização e pela servicificação.

Isso porque, ao passo em que as atividades nos países desenvolvidos se concentram de maneira crescente em serviços industriais de alto valor agregado, observa-se uma tendência de redução da importância relativa da indústria em diversas dimensões (como a participação no PIB, no emprego, na formação bruta de capital fixo etc.). Estes fatos, por sua vez, têm suscitado o debate na literatura 
acerca das limitações da sustentabilidade do desenvolvimento (com aumento da produtividade, formação de um mercado de consumo de massas e distribuição de renda ao menos funcional ao crescimento) amparado fundamentalmente em um processo de servicificação e desindustrialização da economia. Tais questionamentos apresentam-se ainda de maneira mais intensa em economias emergentes como Brasil e México, visto que estes países têm sua estrutura industrial fortemente questionada pela concorrência da fábrica asiática ao mesmo tempo em que, em suas economias, o processo de servicificação restringe-se fundamentalmente a atividades de baixa complexidade tecnológica e baixo valor agregado. Nesse sentido, apresentam-se algumas considerações na próxima seção sobre a relação entre essa nova divisão internacional do trabalho com centralidade do papel da economia chinesa como workshop of the world e os impactos na estrutura produtiva global.

\section{Mudanças estruturais e os impactos da reorganização da cadeia produtiva global em países selecionados}

As mudanças nas estruturas produtivas globais, da segunda metade da década de 1990 ao período recente, associadas ao intenso processo de globalização e esgotamento do paradigma tecno-econômico do século $\mathrm{XX}$, têm levado à reconfiguração da indústria manufatureira mundial. Nesse sentido, o estudo sobre as mudanças estruturais dos países tem despertado sobremaneira o interesse da literatura econômica desde a década de 1980. O principal motivo desse interesse está na verificação da perda da participação industrial no total da economia dos países não asiáticos e na conseguinte diminuição da capacidade destas estruturas industriais nacionais contribuírem para o crescimento econômico de longo prazo.

Assim, esta seção tem como objetivo analisar as transformações estruturais na indústria global entre 2000 e 2014 a partir da dimensão produtiva. Dessa maneira, avaliam-se as mudanças dos países selecionados por meio do emprego e do VA industrial, além de analisar o nível de produtividade total da economia em relação à fronteira internacional.

Para analisar a evolução do nível de produtividade em relação à fronteira internacional, foram utilizados dados da WIOD Socio-Economic Accounts Database provenientes da GGDC - Groningen Growth and Development Centre, a um nível de desagregação a dois dígitos em 19 atividades manufatureiras. A fim 
de eliminar os efeitos das variações cambiais, os valores em moedas nacionais correntes (nominais) foram calculados levando em consideração a taxa de paridade de poder de compra (P.P.P) em relação ao dólar estadunidense para a economia em geral. Assim, define-se que P.P.P representa a taxa na qual a moeda de um país teria que ser convertida na de outro país para comprar a mesma quantidade de bens e serviços em cada país ${ }^{3}$. O mesmo esforço e recorte (agregação a dois dígitos e sempre que aplicável a partir de consideração dos valores em P.P.P) foi replicado na seção seguinte para se analisar os esforços tecnológicos das respectivas indústrias nacionais, a partir da combinação de dados disponibilizados por instituições como OCDE - Organização para Cooperação e Desenvolvimento Econômico, INDSTAT2 - Industrial Statistics Database - UNIDO (United Nations Industrial Development Organization - e por bases de dados como PINTEC/IBGE - Pesquisa de Inovação Tecnológica, entre outras.

Arend (2015) lembra que economias em desenvolvimento como a China, Índia e Coreia do Sul passaram por um processo de industrialização no período recente, ao passo que Brasil e México apresentaram uma "desindustrialização precoce" e economias desenvolvidas, como EUA e Japão, revelaram uma desindustrialização "natural" ou normal ${ }^{4}$.

O gráfico 1 mostra a participação do VA da indústria manufatureira no total dos setores, no período entre 2000-2014. A China foi o país com maior nível de participação do VA da indústria no total. Esses resultados mantiveram patamares estáveis durante todo o período com uma média de 31,95\%, e a partir de 2006 vem apresentando tendência de decrescimento. Entre 2006 e 2014 a queda foi de 3,33 p.p. e durante todo o período analisado esta foi de 2,6 p.p.. Contudo, segundo os dados da WIOD, o produto industrial chinês, em termos absolutos e medidos em P.P.P, cresceu no período cerca de $499,7 \%$.

\footnotetext{
Definição de P.P.P retirado do sítio institucional do Fórum Mundial Internacional: https://www.imf.org/external/pubs/ft/fandd/basics/p.p.p.htm.

${ }^{4}$ Dado o fato de, a partir de certo nível de renda per capita (ao redor de US\$ 20 mil (Arend, 2015, p. 25)) a elasticidade renda da demanda por produtos industriais reduz-se significativamente em relação à elasticidade renda da demanda por serviços.
} 


\section{Gráfico 1 - Participação Percentual do Valor Adicionado da Indústria Manufatureira no Total dos Setores, países selecionados (2000-2014)}

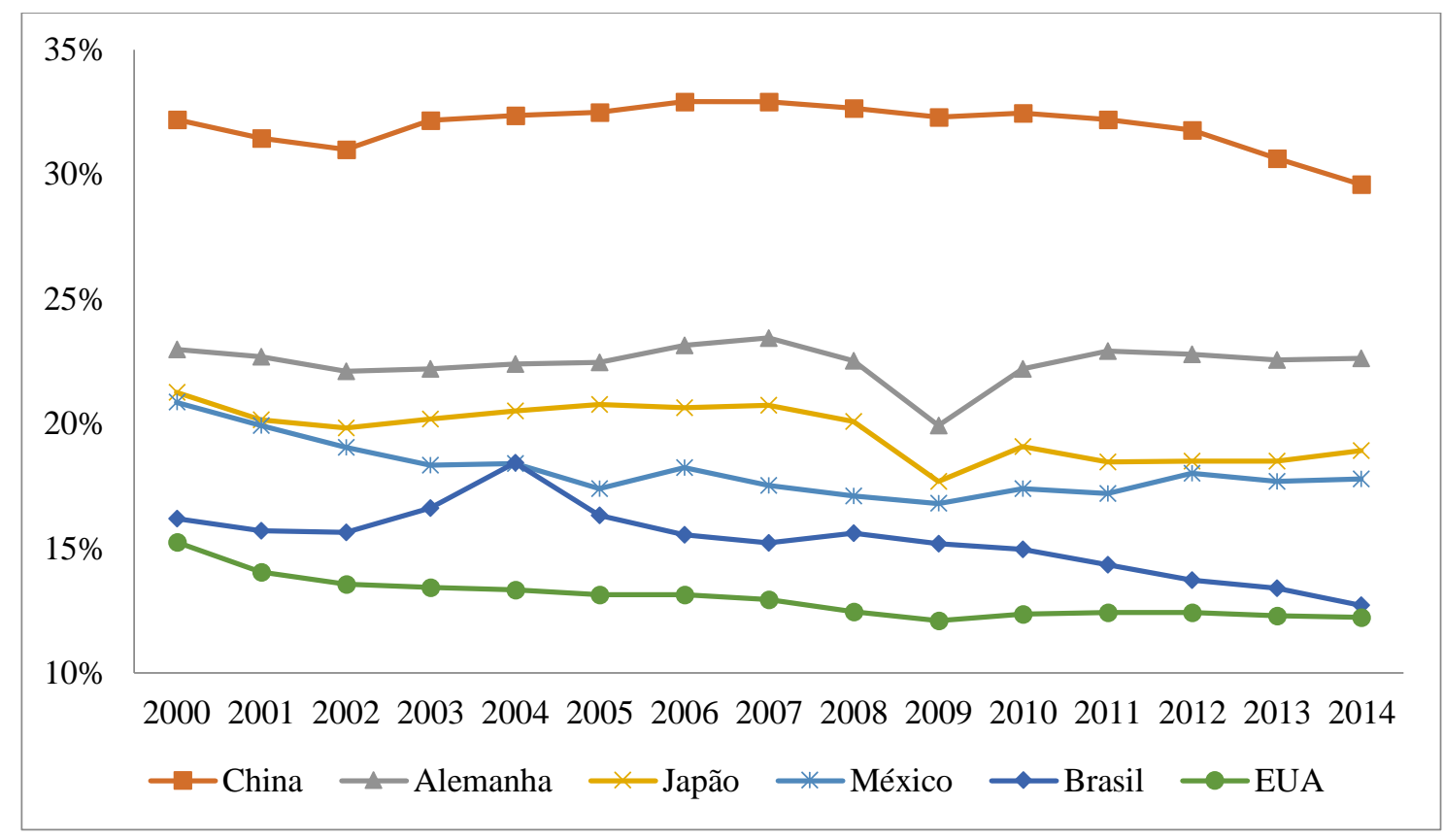

Nota: $V A$ total $=V A_{\text {Agricultura }}+V A_{\text {Mineração }}+V A_{\text {Manufatura }}+V A_{\text {Serviços }}$ Fonte: elaboração própria com base nos dados do WIOD/GGDC.

Pelas óticas do VA e do emprego, uma perda do share do VA industrial em relação ao PIB e uma queda do emprego industrial em relação aos demais setores, em países cuja renda per capita é razoavelmente alta, representa uma desindustrialização "natural", tal qual é observada para os EUA, Alemanha e Japão. De maneira análoga, uma queda observada por esses indicadores em países em desenvolvimento significa uma desindustrialização "precoce". Em outras palavras, ter um alto nível de participação desses indicadores significa que o país possui resultados relativos exitosos sobre os efeitos do processo de industrialização, de acordo com a literatura tradicional sobre desindustrialização.

Nesse sentido, o gráfico mostra que a indústria de transformação brasileira apresentou em 2014 o segundo pior resultado dentre os países analisados. A estrutura do VA da indústria manufatureira representava 16,18\% do PIB em 2000 , valor que se mostrou abaixo da indústria mexicana $(20,85 \%)$, sendo que em 2014 passou a representar 12,70\% do total, uma variação de -3,48 p.p.. Apesar de em termos absolutos a indústria crescer, a partir desses resultados pode-se dizer que Brasil e México apresentaram tendência de um processo de desindustrialização prematura. 
Em síntese, pode-se inferir que o Brasil apresentou as maiores quedas em pontos percentuais da participação do VA da indústria de transformação em proporção do total de setores, no período entre 2000-2014. Vale ressaltar que todos os países apresentaram variações negativas da participação do VA da manufatura, no período todo. As menores quedas no período todo foram observadas para o Alemanha e Japão e as maiores para Brasil, México e EUA.

No tocante às mudanças nos padrões estruturais pela ótica do emprego, o gráfico 2 apresenta a participação do emprego industrial no emprego total da economia de países selecionados no período 2000-2014. A China, mais uma vez, destaca-se por apresentar um alto crescimento. O país evidenciou uma participação estável no emprego industrial, com média de 14,54\% entre 2000 e 2003. A partir de 2004, a participação do pessoal empregado na indústria seguiu tendência de crescimento até 2012 quando atigiu a marca de 20,79\%. Assim, tem-se afirmado com os maiores níveis de participação entre os países da amostra desde 2008. Entre 2000 e 2014, a participação do emprego industrial chinês cresceu 4,27 p.p.. Em números absolutos, em 2014, a indústria chinesa apresentava 168,3 milhões de empregados, cerca de 13 vezes a mais do que a indústria estadunidense.

\section{Gráfico 2 - Participação Percentual do Emprego Industrial no Emprego Total, países selecionados, em (\%) (2000-2014)}

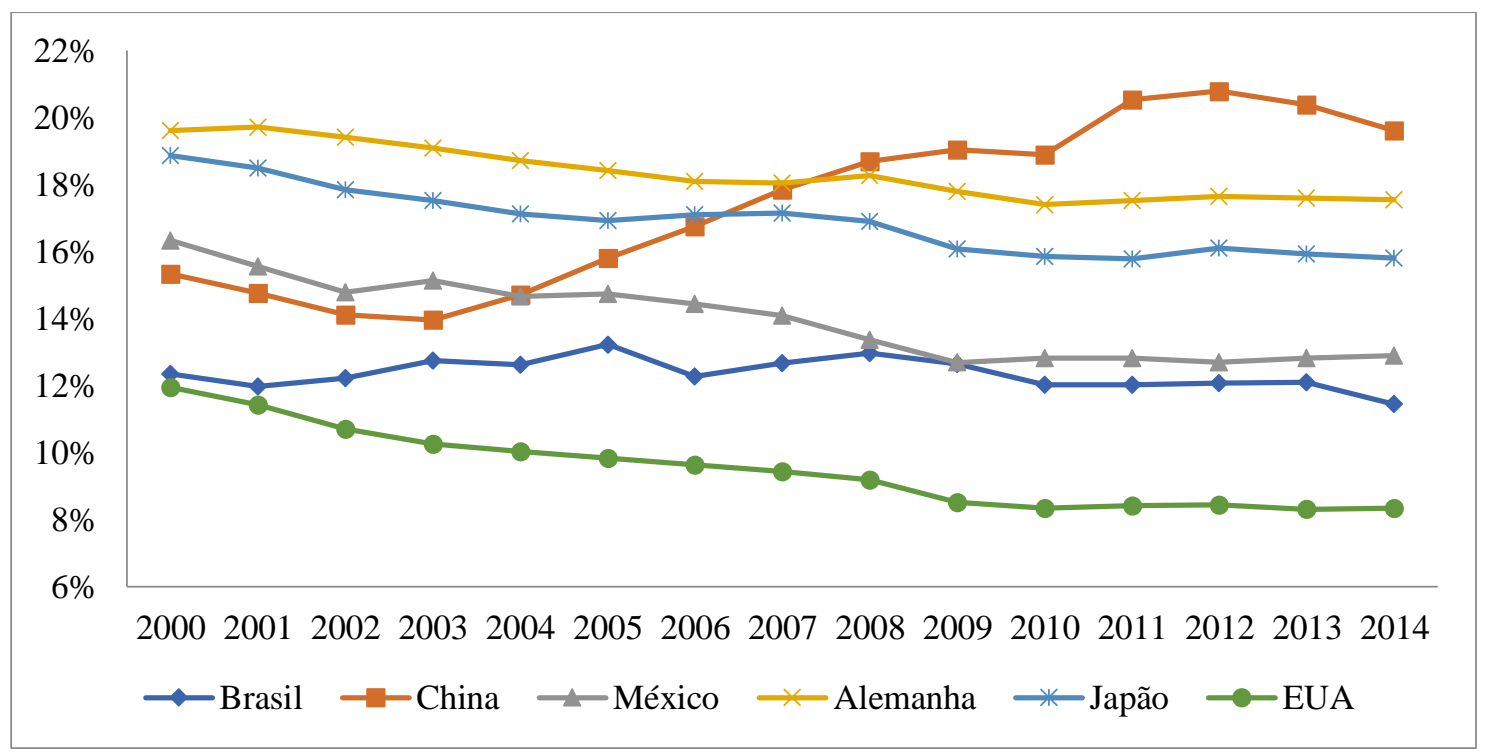

Fonte: elaboração própria com base nos dados da WIOD/GGDC. 
Alemanha, Japão, EUA, Brasil e México apresentaram quedas nos níveis de participação de empregados na indústria. Dessa maneira, por esse indicador inferese que todos os países, com exceção da China, passam por um fenômeno de desindustrialização, ainda que relativa.

O panorama industrial brasileiro pela ótica do emprego mantém-se razoavelmente estável durante todo o período com média de $12,35 \%$ da participação dos empregados no setor, com tendência de queda entre 2008-2014. O maior nível de participação do emprego industrial foi de 13,25\% apresentada para o ano de 2005. O país apresentou-se como segundo em pior desempenho nesse indicador, chegando em 2014 com uma taxa de 11,44\%, atrás somente dos EUA.

Comparativamente, os níveis de participação do emprego industrial brasileiro, apesar de serem próximos aos EUA, não significam um bom desempenho da economia brasileira, uma vez que deve-se levar também em consideração o nível de desenvolvimento do país, mensurado por meio da renda per capita. A renda per capita dos EUA representa cerca de sete vezes a mais do que a renda per capita brasileira, segundo dados do Banco Mundial para 2018. Assim, a desindustrialização relativa estadunidense é natural, enquanto que a brasileira é considerada prematura.

Outro ponto a se destacar em comparação a esses dois países é que, no caso brasileiro, o indicador de emprego se mantém estável em função de setores de baixa complexidade, baixo conteúdo tecnológico e intensivo em mão de obra. Assim, concentra-se sua mão de obra primordialmente em setores tradicionais como, por exemplo, o setor de alimentos e bebidas. No caso do emprego estadunidense, há uma importante reconfiguração setorial cujo emprego concentra-se em atividades de serviços intensivos em conhecimento, que são de alta complexidade.

De forma resumida, a tabela 1 mostra a mudança estrutural pela ótica do VA e do emprego da manufatura e seus impactos no crescimento médio anual da produtividade. No período de 2000 a 2014, todos os países apresentaram queda no VA industrial, em contrapartida com o crescimento do VA do setor de serviços. Por sua vez, os empregos industriais também apresentaram queda, com exceção da China. O processo de mudança estrutural parece seguir tendência para o setor de serviços, que cresceu de maneira difundida em todos os países, com maior variação de crescimento do VA de serviços (7,8 p.p.) e do emprego (17,2 p.p.) chineses. 
Tabela 1 - Mudança Estrutural pela ótica do Valor Adicionado e Emprego Setorial, em pontos percentuais, Crescimento Médio Anual da Produtividade, em \%, países selecionados (2000-2014)

\begin{tabular}{|c|c|c|c|c|c|c|c|c|}
\hline \multirow[b]{2}{*}{ Países } & \multirow[b]{2}{*}{ Setores } & \multicolumn{2}{|c|}{ Valor Adicionado } & \multicolumn{3}{|c|}{ Empregos } & \multicolumn{2}{|r|}{$\begin{array}{c}\text { Crescimento da } \\
\text { Produtividade }\end{array}$} \\
\hline & & $2000-2007$ & $2007-2014$ & $2000-2014$ & $2000-2007$ & $2007-2014$ & $2000-2014$ & 2000-2014 \\
\hline \multirow{4}{*}{ Brasil } & Agricultura & 0,0 & 0,0 & 0,0 & $-3,1$ & $-3,8$ & $-6,9$ & 13,8 \\
\hline & Mineração & 1,4 & $-0,2$ & 1,2 & 0,0 & $-0,2$ & $-0,2$ & 48,7 \\
\hline & Manufatura & $-1,0$ & $-2,5$ & $-3,5$ & 0,3 & $-1,2$ & $-0,9$ & 15,6 \\
\hline & Serviços & $-0,4$ & 2,7 & 2,3 & 2,7 & 5,3 & 8,0 & 16,9 \\
\hline \multirow{4}{*}{ China } & Agricultura & $-4,4$ & $-1,2$ & $-5,7$ & $-10,1$ & $-11,7$ & $-21,9$ & 14,5 \\
\hline & Mineração & 0,0 & 0,4 & 0,5 & $-0,2$ & 0,6 & 0,4 & 29,3 \\
\hline & Manufatura & 0,7 & $-3,3$ & $-2,6$ & 2,5 & 1,8 & 4,3 & 24,2 \\
\hline & Serviços & 3,7 & 4,1 & 7,8 & 7,8 & 9,4 & 17,2 & 21,2 \\
\hline \multirow{4}{*}{ México } & Agricultura & $-0,5$ & 0,0 & $-0,5$ & $-1,1$ & 0,4 & $-0,7$ & 6,7 \\
\hline & Mineração & 2,4 & $-1,1$ & 1,3 & 0,2 & 0,0 & 0,3 & 38,5 \\
\hline & Manufatura & $-3,3$ & 0,3 & $-3,1$ & $-2,3$ & $-1,2$ & $-3,4$ & 26,8 \\
\hline & Serviços & 1,5 & 0,8 & 2,3 & 3,1 & 0,7 & 3,9 & 22,7 \\
\hline \multirow{4}{*}{ Alemanha } & Agricultura & $-0,2$ & $-0,1$ & $-0,4$ & $-0,2$ & $-0,1$ & $-0,4$ & 11,9 \\
\hline & Mineração & 0,0 & 0,0 & $-0,1$ & $-0,1$ & $-0,1$ & $-0,2$ & 32,0 \\
\hline & Manufatura & 0,5 & $-0,8$ & $-0,4$ & $-1,6$ & $-0,5$ & $-2,1$ & 29,6 \\
\hline & Serviços & $-0,2$ & 1,0 & 0,8 & 1,9 & 0,7 & 2,6 & 24,6 \\
\hline \multirow{4}{*}{ Japão } & Agricultura & $-0,3$ & 0,1 & $-0,3$ & $-0,9$ & $-0,3$ & $-1,2$ & 15,8 \\
\hline & Mineração & $-0,1$ & 0,1 & $-0,1$ & 0,0 & 0,0 & $-0,1$ & 40,3 \\
\hline & Manufatura & $-0,5$ & $-1,8$ & $-2,3$ & $-1,7$ & $-1,3$ & $-3,1$ & 28,5 \\
\hline & Serviços & 1,0 & 1,7 & 2,7 & 2,6 & 1,6 & 4,3 & 25,5 \\
\hline \multirow{4}{*}{ EUA } & Agricultura & 0,0 & 0,3 & 0,3 & $-1,1$ & 0,4 & $-0,7$ & 32,8 \\
\hline & Mineração & 1,1 & 0,4 & 1,5 & 0,2 & 0,0 & 0,3 & 52,1 \\
\hline & Manufatura & $-2,3$ & $-0,7$ & $-3,0$ & $-2,3$ & $-1,2$ & $-3,4$ & 36,3 \\
\hline & Serviços & 1,2 & 0,0 & 1,2 & 3,1 & 0,7 & 3,9 & 29,8 \\
\hline
\end{tabular}

Fonte: elaboração própria com base nos dados da WIOD/GGDC.

O maior crescimento médio anual da produtividade no período 2000-2014 foi observado, para todos os países, no setor de mineração, sendo o maior crescimento nos EUA (52,1\%), seguido por Brasil (48,7\%). De fato, os EUA apresentaram as maiores produtividades e os maiores níveis de crescimento médio anual da produtividade no período para todos os setores. O segundo maior nível de crescimento da produtividade estadunidense foi a industrial manufatureira, chegando a 36,3\%. Em seguida aos EUA, os países que apresentaram maiores crecimento da produtividade industrial foram Alemanha $(29,6 \%)$ e Japão $(28,5 \%)$. O Brasil obteve o menor nível de crescimento médio da produtividade, entre os países analisados, com apenas $15,6 \%$, bem abaixo da taxa observada para a indústria mexicana $(26,8 \%)$. Esses resultados indicam a dificuldade da indústria brasileira em atingir um processo de mudança estrutural que fomente a eficiência dinâmica tanto na dimensão keynesiana quanto schumpeteriana e, por conseguinte, contribua positivamente para o catching up. Ou seja, uma mudança 
estrutural que promova o aumento da participação de setores com maior dinamismo tecnológico, maiores níveis de produtividade e maiores elasticidades renda da demanda.

De maneira geral, constata-se que o setor industrial de países desenvolvidos e em desenvolvimento segue tendência de queda na participação de empregos, uma vez que Alemanha, Japão, Brasil, México e EUA apresentaram variações percentuais negativas no período 2000-2014. Por outro lado, a China foi o único país a apresentar variação positiva.

Ademais, compreende-se que há um movimento, de maneira difundida, de aumento da participação do emprego e do VA em setores de serviços tanto em países desenvolvidos quanto em países em desenvolvimento. Esse processo pode estar associado a servicificação das atividades manufatureiras globais. Entretanto, os dados agregados não permitem a verificação de tal fenômeno. Vale ressaltar que, dentre os países analisados, a China foi o país que apresentou o maior incremento na participação do emprego individual na indústria manufatureira no período $(4,3$ p.p.), inclusive com maior variação negativa do emprego e do VA no setor de agricutura (-21,9 p.p. e -5,7 p.p., respectivamente) e maiores variações positivas no emprego e do VA no setor de serviços (17,2 p.p. e 7,8 p.p., respectivamente).

Dessa maneira, pela ótica do VA e do emprego, foi possível constatar evidências que sugerem um processo de desindustrialização relativa nos países analisados, o qual está associado a impactos no potencial de aumento de produtividade da economia. Nesse sentido, a próxima seção busca analisar a competitividade da indústria brasileira em perspectiva comparada por meio da produtividade do trabalho manufatureiro, além de quantificar o grau de aproximação das atividades da indústria brasileira em relação a fonteira.

\section{As transformações na estrutura produtiva brasileira face à fronteira internacional}

Os resultados da perda de participação do emprego industrial em países desenvolvidos apresentados na seção anterior estão em conssonância com a literatura, conforme pode ser observado a partir do conceito de desindustrialização presente no trabalho de referência de Rowthorn e Weels (1987, p. 5), segundo o qual a desindustrialização é um "termo que tem muitos significados diferentes, mas através desse trabalho nós o usaremos para denotar uma queda na participação 
da indústria, especialmente a manufatureira, no emprego total". Nesta mesma perspectiva, dada a complexidade do fenômeno, Tregenna (2008) defende que

\begin{abstract}
ao invés de definir desindustrialização em termos de uma simples dimensão de queda de participação da manufatura no emprego total, assim como na literatura corrente, nós propomos que a desindustrialização poderia ocorrer quando existe um declínio sustentado em ambas a participação da manufatura no emprego total e a participação da manufatura no PIB (Tregenna, 2008, p. 459, itálicos no original).
\end{abstract}

Neste sentido, parece que há um movimento de desindustrialização desses países (com exceção da China) uma vez que se observaram quedas nas participações do VA da indústria manufatureira no PIB e quedas na participação do emprego industrial no total da economia.

Palma (2005, p. 4) lembra que desde o final dos anos 1960 vêm sendo desenvolvidas hipóteses que tentam explicar a queda do emprego industrial em países industrializados. O autor apresenta quatro principais hipóteses: 1) a queda é uma "ilusão estatística" provocada pela realocação de mão de obra industrial para o setor de serviços, sendo esse serviço terceirizado pela indústria manufatureira; 2) a redução do emprego pode estar relacionada a uma significativa redução na elasticidade renda da demanda por produtos manufaturados; 3) "o declínio é consequência do rápido aumento de produtividade (pelo menos em alguns setores) na indústria trazido pela propagação do novo paradigma tecnológico de microeletrônicos (esse teria sido um caso da nova tecnologia tender a produzir 'crescimento de desempregados')"; 4) a queda é o resultado de uma nova divisão internacional do trabalho. De maneira geral, o autor conclui que tais hipóteses podem estar associadas a diferentes causas do processo de desindustrialização, as quais também são determinadas pelos níveis de desenvolvimento das forças produtivas de cada nação.

Deste modo, estabelecendo uma relação com o trabalho de Rowthorn e Wells (1987), em países com elevado nível de renda per capita tal desindustrialização se apresentaria como um fenômeno positivo, resultado principalmente da redução da elasticidade renda da demanda por produtos manufaturados. Em contrapartida, o mesmo fenômeno teria causas completamente distintas em países com níveis de renda per capita relativamente baixos e desenvolvimento das forças produtivas incipiente, caracterizando-se como precoce. 
Neste contexto de transformações tecnológicas nos países desenvolvidos se observa a existência de fronteiras cada vez mais difusas entre as atividades tradicionalmente manufatureiras e um conjunto amplo de serviços estritamente vinculados à indústria como realização de atividades de $\mathrm{P} \& \mathrm{D}$, consultorias especializadas, serviços de engenharia, gestão de marcas, atividades de design, entre outros, que fazem com que fenômenos como desindustrialização e servicificação (principalmente em países desenvolvidos) tenham que ser compreendidos de maneira integrada. Entretanto, cabe destacar que apesar do aumento da importância relativa deste processo de servicificação, tem-se observado um questionamento crescente inclusive em países desenvolvidos da capacidade dos serviços de alta intensidade tecnológica liderarem o processo de transformação estrutural e viabilizarem estratégias de desenvolvimento sustentáveis em longo prazo. Isso porque, a despeito dos elevados valores agregados possibilitados por tais serviços, há receios de que a desvinculação geográfica crescente destes da produção tenha efeitos no longo prazo no potencial de aprendizado tecnológico local e, por conseguinte, no aumento da produtividade, na geração de empregos e na sustentação do dinamismo dos mercados de massa domésticos.

A sustentação desta trajetória de desenvolvimento, por sua vez, tem como fundamento a capacidade de se fomentar um processo de transformação estrutural que promova o aumento da participação relativa de atividades com maiores níveis de produtividade. Para tal é necessário que a acumulação esteja associada a um ciclo virtuoso materializado em reinvestimentos com vistas à constante incorporação de progresso técnico nas atividades produtivas.

Assim, uma vez que alguns dos principais determinantes para o aumento de produtividade dos países estão relacionados com as mudanças nas técnicas e inovações na dimensão produtiva, destaca-se a importância da existência de um denso parque produtivo doméstico para se potencializar este movimento. De maneira complementar, destaca-se a importância do papel da P\&D interna ou externas às empresas, que viabiliza a produção de novo conhecimento útil, além de aumentar a capacidade de absorver conhecimento externo por meio da ampliação do aprendizado tecnológico, conforme Cohen e Levinthal (1989). A intensificação desta, por sua vez, ocorreria quando associada à consolidação de um sistema nacional de inovação que promova fluxos de conhecimento entre os 
agentes, potencializando o aprendizado coletivo (Freeman, 1995; Lundvall, 1992) dentro de uma estrutura científica e produtiva densa. Deste modo, se configurariam como elementos viabilizadores de uma estratégia de catching up (Chang, 2004), com redução do gap de produtividade.

A partir dessa constatação, observa-se que o processo de mudança tende a ser gradativo e path-dependent e está relacionado com os níveis de produtividade dos países, que definem as lacunas entre os líderes e os seguidores. Contudo, cada país segue uma trajetória de desenvolvimento diferente, que depende do modo como são construídas as competências tecnológicas internas. Nesse sentido, as mudanças na dimensão produtiva, técnica e na inovação parecem ser fundamentais para a promoção dos aumentos de produtividades dos países. Dessa forma, alguns países avançam no sentido de recuperar o atraso (catching up) em comparação aos que estão na fronteira internacional por meio do aumento de produtividade, enquanto que outras economias seguem devagar ou retrocedem (falling behind) (McMillan; Rodrik, 2011).

Tendo como base tal discussão, esta seção procura mensurar o distanciamento relativo da indústria manufatureira dos países analisados neste trabalho a partir de seus respectivos gaps de produtividade (segmentados segundo intensidade tecnológica dos setores, a partir da OCDE (1987)). O gap de ou diferencial de produtividade é definido neste trabalho como a distância entre os valores da produtividade de um setor em determinado país e a produtividade deste mesmo setor nos EUA ${ }^{5}$. Assim, a título de ilustração, o valor do gap de produtividade da indústria manufatureira ser $64 \%$ significa que esta é $64 \%$ menos produtiva que a indústria manufatureira dos EUA. Por definição, quando um determinado setor de um país aumenta seu gap de produtividade em relação ao mesmo setor dos EUA, ele encontra-se em processo de falling behind. Caso haja uma redução deste gap, verifica-se um processo de catching up.

Ressalta-se que a produtividade é medida pela razão entre VA em P.P.P e pessoal ocupado. Vale lembrar que, devido à limitação de disponibilidade de dados, a mensuração destes gaps restringiu-se ao período 2000-2014 para todos os

${ }^{5} \mathrm{O}$ gap de produtividade em relação à fronteira $(\mathrm{EUA}=0 \%)$ é mensurado pela fórmula: $G A P=1-$ $\left(V A_{P a i ́ s} X / V A_{E U A}\right)$. Ainda, pode ser interpretado, quanto maior o valor (ou próximo a 100\%) o gap entre os países é maior. Valores negativos representam que o país possui produtividade superior a da fronteira, caracterizando forging ahead. A variação percentual, no período, significa uma diminuição no gap quando apresenta valores negativos. 
países selecionados. O esforço e contribuição deste trabalho é apresentar uma leitura em perspectiva comparada dos processos de transformação produtiva dos países selecionados.

Assim, o Brasil apresentou aumento do gap de produtividade em todos os grupos de setores agregados por intensidade tecnológica, no período 2000-2014, principalmente aqueles de média-alta intensidade tecnológica, com uma variação de 25,1 p.p. (Tabela 2). Vale ressaltar que a menor lacuna de produtividade da indústria brasileira foi no grupo de setores de média-alta intensidade tecnológica no ano de 2000, com uma produtividade superior a 50\% em relação à fronteira tecnológica.

Nota-se que nos setores de alta tecnologia, o país se destacou, dentre os países selecionados, por apresentar a menor variação do gap de produtividade, que representava 13,3 p.p. no período. Contudo, dado o nível de agregação dos dados e os limites desse artigo, impossibilita-se o aprofundamento analítico para afirmar com clareza quais são os determinantes dessas diferenças observadas entre os países. Entretanto, identifica-se que se abre uma agenda de pesquisa futura que proporcione a investigação de tais determinantes. 
Tabela 2 - Gap de Produtividade do Trabalho na Indústria Manufatureira em relação aos EUA, em P.P.P, por intensidade tecnológica, em \%, variação em pontos percentuais $(2000-2014)$

\begin{tabular}{|c|c|c|c|c|c|}
\hline Países & Setores OCDE & 2000 & 2007 & 2014 & $\begin{array}{c}\text { Variação } \\
(2000-2014)\end{array}$ \\
\hline \multirow{5}{*}{ Brasil } & Alta & 59,4 & 66,9 & 72,7 & 13,3 \\
\hline & Média-alta & 49,3 & 60,9 & 74,4 & 25,1 \\
\hline & Média-baixa & 66,9 & 74,2 & 72,2 & 5,3 \\
\hline & Baixa & 77,8 & 82,3 & 82,5 & 4,8 \\
\hline & Total & 74,1 & 80,0 & 81,5 & 7,4 \\
\hline \multirow{5}{*}{ China } & Alta & 87,4 & 86,4 & 86,6 & $-0,8$ \\
\hline & Média-alta & 86,3 & 83,1 & 81,6 & $-4,8$ \\
\hline & Média-baixa & 86,2 & 77,6 & 73,0 & $-13,2$ \\
\hline & Baixa & 87,5 & 84,1 & 80,2 & $-7,3$ \\
\hline & Total & 87,8 & 83,5 & 80,8 & $-7,0$ \\
\hline \multirow{5}{*}{ México } & Alta & 53,7 & 69,7 & 76,6 & 23,0 \\
\hline & Média-alta & 39,9 & 48,8 & 47,7 & 7,8 \\
\hline & Média-baixa & 37,0 & 49,4 & 45,7 & 8,7 \\
\hline & Baixa & 50,6 & 52,8 & 50,0 & $-0,5$ \\
\hline & Total & 49,3 & 57,1 & 55,9 & 6,6 \\
\hline \multirow{5}{*}{ Alemanha } & Alta & 19,7 & 20,4 & 44,3 & 24,5 \\
\hline & Média-alta & 26,8 & 26,8 & 36,3 & 9,5 \\
\hline & Média-baixa & 24,2 & 34,0 & 39,7 & 15,5 \\
\hline & $\underline{B}$ aixa & 30,5 & 33,7 & 42,2 & 11,7 \\
\hline & Total & 25,9 & 27,5 & 37,3 & 11,4 \\
\hline \multirow{5}{*}{ Japão } & Alta & 48,5 & 56,3 & 64,3 & 15,8 \\
\hline & Média-alta & 40,6 & 41,9 & 53,3 & 12,7 \\
\hline & Média-baixa & 24,3 & 28,6 & 30,6 & 6,3 \\
\hline & Baixa & 32,8 & 34,0 & 35,4 & 2,6 \\
\hline & Total & $\mathbf{3 5 , 8}$ & $\mathbf{3 7 , 8}$ & 45,1 & $\mathbf{9 , 3}$ \\
\hline
\end{tabular}

Nota: os dados utilizados são desagregados a 2-dígitos e foram agregados de acordo com a classificação tradicional da OCDE em setores de Alta (21 Produtos farmacêuticos; 26 - Computadores, produtos eletrônicos e ópticos); Média-Alta (20 - Produtos químicos; 27 - Equipamentos elétricos; 28 Máquinas e equipamentos; 29 - Veículos motores, reboque; 30 - Outros equipamentos de transporte); Média-baixa (19 - Coque e produtos petrolíferos refinados; 22 - Borracha e produtos plásticos; 23 - Produtos não metálicos; 24 Metalurgia; 25 - Produtos de metal; 33 - Reparação e instalação de máquinas e equipamentos); e Baixa tecnologia (10-12 - Alimentos, bebidas e tabaco; 13-15 - Têxtil e vestuário; 16 - Produtos de madeira; 17 - Papel e produtos de papel; 18 - Impressão; 31-32 - Móveis).

Fonte: elaboração própria com base nos dados da WIOD/GGDC. 
A indústria mexicana apresentou um movimento de falling behind, uma vez que ampliou o gap de produtividade em relação à fronteira. Todos os grupos de setores ampliaram, com exceção dos setores de baixa tecnologia, que se manteve estável e com uma variação negativa em torno de 0,5 p.p.. A maior lacuna observada foi nos setores de alta tecnologia, com ampliação do gap em 23 p.p. no período.

A Alemanha foi o país a apresentar menor gap de produtividade total da manufatura no ano 2000 (25,9\% abaixo da estadunidense). Apesar de ampliar o gap de produtividade total da manufatura, com uma variação percentual de 11,4 p.p., a Alemanha continua o mais próximo à fronteira. $\mathrm{O}$ país perdeu posicionamento em relação à fronteira em setores de alta tecnologia, com uma ampliação da lacuna em 24,5 p.p., sendo o maior gap observado para o país. Destaca-se que todos os grupos de setores apresentaram um fenômeno de falling behind. Esses resultados estão de acordo com van Ark, O'Mahoney e Timmer (2008), que encontraram um processo de falling behind para os países da União Europeia entre 1995 e 2006.

Similarmente à Alemanha, a indústria japonesa ampliou o gap em setores de alta intensidade tecnológica, como a maior ampliação do gap de produtividade no conjunto da indústria japonesa (em torno de 15,8 p.p.). Ainda se observou que todos os setores se encontraram em movimento de falling behind, com um aumento da lacuna de produtividade no total da indústria (9,3 p.p.).

A China foi o único país da amostra a apresentar ganhos de produtividade da manufatura total em relação à fronteira tecnológica, diminuindo o diferencial em relação à economia estadunidense. O país diminuiu o gap em todos os setores agregados, com menor variação negativa para os setores de alta tecnologia que se mantiveram em patamares estáveis no período 2000-2014. A menor distância observada foi para os setores de média-baixa tecnologia, com variação de $-13,2$ p.p.

Cumpre ressaltar que, em geral, o gap de produtividade chinês é o mais elevado em relação aos demais países e para todos os setores. Isso porque apesar de a economia chinesa apresentar um número crescente de empresas em estágio avançado de catching up, e em posição até de contestação de líderes tradicionais em diversos setores (como os casos de Huawei, Lenovo, Alibaba, Tencent, Midea, 
Xiaomi, Op.p.o, Haier, entre outras), a estrutura produtiva local é bastante heterogênea no que diz respeito ao grau de produtividade e sofisticação tecnológica.

Ou seja, tal qual é historicamente característico de economias periféricas, o avanço tecnológico em determinadas atividades ocorre em paralelo à reprodução da heterogeneidade nas suas mais diversas dimensões (produtiva, regional e social) (Futado, 1961). Isso posto, a China mostrou um rápido crescimento da produtividade e com diminuição do gap em relação aos EUA em pouco tempo, mostrando indícios de um processo de catching up industrial.

Dessa maneira, o processo de mudança estrutural observado para os países da amostra em geral não tem contribuído para o processo de convergência de produtividade a padrões competitivos internacionais. Apesar dos baixos níveis de produtividade, a economia chinesa foi a única a diminuir o gap de produtividade. Entretanto, cabe destacar que, apesar de o processo de transformação estrutural chinesa estar relacionado a uma tendência de redução do gap de produtividade no período analisado, ressalta-se que a magnitude deste gap ainda é bastante elevada. Ou seja, tal qual sugerido por Nolan (2014), apesar de a capacidade da política industrial, científica e tecnológica chinesa fomentar importantes avanços em sua estrutura produtiva, tal processo ainda apresenta limitações no que diz respeito à capacidade de viabilizar a inserção das empresas locais em áreas com maior capacidade de agregação de valor nas CGV.

Assim, vale ressaltar que o indicador mensura o gap de produtividade a partir do VA (e não pelo valor bruto da produção) por trabalhador, em que os insumos e componentes importados não são computados no cálculo do VA. Este expediente, por sua vez, contorna as limitações de um suposto efeito maquila que tenderia a inflar os valores da produção da indústria chinesa em segmentos onde a participação desta nas CGV concentra-se principalmente nas etapas de montagem.

Neste contexto, a figura 1 sintetiza a comparação da indústria brasileira em relação à fronteira. Para a construção da figura, inicialmente verificou-se o nível de crescimento do VA para todos os setores da indústria de transformação mundial entre 2000 e 2014. Em seguida, os setores foram agrupados em dois blocos: aqueles que apresentaram dinamismo acima da média e aqueles que apresentaram dinamismo abaixo da média.

A partir deste agrupamento, mensurou-se para o ano de 2014 a produtividade de cada um destes setores na unidade de referência entendida como 
fronteira tecnológica (economia estadunidense). Novamente os setores foram agrupados em dois blocos: aqueles com produtividade maior que a média e aqueles com produtividade menor que a média.

Como resultado da intersecção destes dois passos, a figura 1 estruturou-se em quatro quadrantes, os quais classificam os setores em (i) mais dinâmicos e com maior produtividade, (ii) menos dinâmicos e com maior produtividade, (iii) menos dinâmicos e com menor produtividade e (iv) mais dinâmicos e com menor produtividade. Imediatamente à frente da descrição dos setores ainda são apresentadas duas informações: o gap da produtividade do setor brasileiro em relação à produtividade do mesmo setor nos EUA (em \%) e a variação deste valor entre os anos de 2000 e 2014.

Assim, por exemplo, a título de ilustração, verifica-se que o setor de fabricação de produtos químicos encontra-se no bloco de setores com crescimento maior que a média da indústria mundial entre 2000 e 2014 e apresenta produtividade maior que a média da indústria americana em 2014. Adicionalmente, o gap de produtividade da indústria brasileira neste setor em 2014 era de $87 \%$. Por fim, observa-se que entre 2000 e 2014 a produtividade deste setor no Brasil reduziu-se em 19 p.p. em relação a sua produtividade nos EUA. Ou seja, infere-se que o gap de produtividade brasileira deste setor em 2000 era de $67 \%$ e, em 2014 passou a representar 87\%, o que denota que o referido setor se encontra em movimento de falling behind em relação à fronteira tecnológica.

Vale destacar ainda que, a fim de se compreender qualitativamente a importância dos setores, estes são ordenados dentro dos quadrantes segundo ordem decrescente de produtividade na economia que representa a fronteira tecnológica (EUA). Deste modo, por exemplo, o setor de fabricação de coque e produtos petrolíferos refinados é o que apresenta a maior produtividade em seu quadrante na economia dos EUA, o setor de computadores e produtos eletrônicos é o que apresenta maior produtividade na economia dos EUA entre os setores que compõem o quadrante 'setores menos dinâmicos e com maior produtividade', e assim sucessivamente.

Explicada a maneira de compreensão da figura 1, a grande constatação é a de que se observa um processo generalizado de aumento do gap de produtividade, ou seja, de falling behind da indústria brasileira, o qual parece ser independente do nível de dinamismo dos setores bem como de seu patamar de produtividade (com 
o agravante de ser aparentemente mais intenso nos setores com maior produtividade). As únicas exceções a este processo são os processos de catching up em móveis (no quadrante dos setores menos dinâmicos e com menor produtividade) e o setor de fabricação de coque e produtos petrolíferos refinados (setores mais dinâmicos e com maior produtividade).

Figura 1 - Catching up ou falling behind? Desempenho dos setores brasileiros face à fronteira internacional (em P.P.P), 2000-2014

\begin{tabular}{|c|c|}
\hline Setores menos dinâmico e com maior produtividade & Setores mais dinâmico e com maior produtividade \\
\hline $\begin{array}{c}\text { Computadores, produtos eletrônicos e ópticos }(79 \% ; 6 \mathrm{pp}) \\
\text { Veículos motores, reboque }(66 \% ; 26 \mathrm{pp})\end{array}$ & $\begin{array}{c}\text { Produtos químicos }(87 \% ; 19 \mathrm{pp}) \\
\text { Produtos farmaceuticos }(71 \% ; 23 \mathrm{pp})\end{array}$ \\
\hline Outros equipamentos de transporte (73; $19 \mathrm{pp})$
\end{tabular}

Fonte: elaboração própria com base nos dados da WIOD/GGCD.

Em síntese, o fenômeno de aumento do gap da produtividade da indústria brasileira, ou seja, falling behind, está em aderência com as conclusões de Diegues e Rossi (2017). Segundo os autores, tais transformações teriam se intensificado em um cenário de Doença Brasileira, “entendida como processo de reconfiguração estrutural em direção à especialização regressiva e à desindustrialização em paralelo ao surgimento de estratégias que garantiram a acumulação do capital investido na esfera industrial na primeira década de 2000”. Assim,

na dimensão produtiva tem-se observado a continuidade de uma tendência desde a década de 1980 de persistente redução da participação da indústria no PIB e de sua contribuição para o crescimento (a qual se situou em patamares próximos a 35\% nos anos 1980 e sistematicamente abaixo de 20\% nos anos 2000). Adicionalmente, além do baixo dinamismo, destaca-se que cerca de $50 \%$ do crescimento do valor da transformação industrial (VTI) entre 2000 e 2010 foi explicado pelos setores intensivos em recursos naturais. Assim, quando se analisa a distribuição percentual do VTI segundo tipos de tecnologia verifica-se que a indústria brasileira tem se concentrado no segmento intensivo em recursos naturais, fenômeno este que se consolida na virada do século e se intensifica ainda mais a partir do final da década de 2000 (Diegues; Rossi, 2017). 
Ao realizar esforço semelhante e analisar em perspectiva comparada as estruturas produtivas latino-americanas e asiáticas, McMillan e Rodrik (2011) reafirmam tal conclusão, ao mostrarem que o processo de globalização parece ter cumprido o seu papel na expansão das oportunidades de empregos de alta produtividade em países asiáticos, principalmente na $\mathrm{China}^{6}$, em contraste do que ocorreu em países da América Latina. Nestes, as oportunidades de emprego seguem na direção oposta, haja vista que setores mais produtivos perdem participação para os menos produtivos. Dessa forma, a globalização parece não ter fomentado o tipo desejável de mudança estrutural, diferente do observado na Ásia (McMillan; Rodrik, 2011).

Contudo, os excelentes resultados da China devem-se também aos grandes esforços tecnológicos que têm levado o país a ser um sucesso no processo de catching up, que é corroborado por diversos indicadores encontrados na literatura, principalmente pelo aumento expressivo dos gastos em $\mathrm{P} \& \mathrm{D}$, além de uma sólida política industrial direcionada a setores do complexo eletrônico.

Melo et al. (2017) analisaram o gap tecnológico das atividades manufatureiras brasileiras em perspectiva comparada a seis países europeus, que são tecnologicamente mais dinâmicos. Denominam-se esses países de fronteira tecnológica. Os autores realizaram uma análise de correspondência (técnica estatística para variáveis qualitativas), em que avaliaram o grau de dinamismo inovativo entre os países por meio de quatro indicadores: i) participação das empresas que realizaram $\mathrm{P} \& \mathrm{D}$ em relação ao total do setor; ii) participação das empresas que inovaram em produto em relação ao total do setor; iii) pessoal ocupado em P\&D e iv) gastos em P\&D. Por fim, Melo et al. (2017) concluíram que o Brasil, Hungria, Croácia e Sérvia compõem um grupo de países cujo dinamismo tecnológico, em geral, é consideravelmente baixo.

Esse estudo, do ponto de vista quantitativo, avança no sentido de analisar por meio de um recorte setorial e também em perspectiva comparada a países

\footnotetext{
${ }^{6}$ McMillan e Rodrik (2011) afirmam que os "fluxos de trabalho de atividades de baixa produtividade para atividades de alta produtividade são o principal motor do desenvolvimento". O resultado desta transformação estrutural pode ser compreendido a partir das dimensões produtiva e tecnológica. Uma análise mais detalhada, porém, transcende os esforços deste artigo e pode ser encontrada em Nolan (2014). Neste sentido, a título de ilustração, enfatiza-se que em 2015 a indústria chinesa produziu $28 \%$ dos automóveis mundiais, $41 \%$ dos navios, $80 \%$ ou mais dos computadores, $90 \%$ ou mais dos celulares. Na dimensão tecnológica observa-se um crescimento de 46,30\% entre 2005 e 2012 da razão entre gastos de P\&D e PIB e de mais de 50\% de seu número de patentes depositadas no Escritório Europeu entre 2005 e 2015.
} 
selecionados, os resultados das transformações estruturais de cada país (nas variáveis de emprego, VA e produtividade do trabalho) em função da reorganização manufatureira global. Em especial, a contribuição dessa pesquisa é mostrar a evolução dos gaps de produtividade entre os grupos de setores tecnológicos dos países em relação aos mesmos setores nos EUA e classificar seus níveis de aproximação. Nesse sentido, a delimitação da fronteira internacional, como foi visto, é baseada na maior produtividade do trabalho dentre os países selecionados, notadamente os EUA.

Assim, a evolução temporal dos resultados dos diferenciais de produtividade (gaps) entre os países e os EUA (i) identificam os níveis de distanciamento dos setores em relação à fronteira tecnológica e (ii) possibilitam uma análise da evolução do distanciamento (ou da aproximação), no período em análise. Outra contribuição importante dessa pesquisa é apresentar uma tipologia que combine essa análise da evolução do catching up (ou do falling behind) da indústria brasileira segundo os diferentes graus de dinamismo internacional dos setores em análise. Assim, permite-se identificar, por exemplo, se o aumento do distanciamento é restrito aos setores com elevado dinamismo no mercado internacional, se o catching up se concentra em setores de menor dinamismo, entre outras segmentações possíveis.

Por outro lado, no caso brasileiro, observa-se que há uma especialização na produção de baixo teor tecnológico principalmente a partir da primarização das commodities seguido por um aumento da participação da indústria baseada em recursos naturais no total da indústria. Nesse sentido, observa-se um atraso brasileiro em setores típicos do paradigma microeletrônico e que "um processo de falling behind marcou a trajetória da indústria brasileira nas últimas décadas" (Arend; Fonseca, 2012, p. 44). Tal especialização em atividades com menor intensidade tecnológica pode ser inferida a partir da análise da estrutura de dispêndios de P\&D e da distribuição do pessoal ocupado (PO) nestas atividades (Tabela 3). 
Tabela 3 - Estrutura dos dispêndios de P\&D da indústria manufatureira (em \%), intensidade de PO em P\&D (em \%), por intensidade tecnológica, países selecionados (2007-2014)

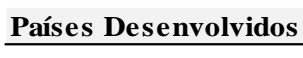

\begin{tabular}{|c|c|c|c|c|c|c|}
\hline \multirow[b]{2}{*}{ Grupo de Setores OCDE } & \multicolumn{2}{|c|}{ Alemanha } & \multicolumn{2}{|c|}{ Japão } & \multicolumn{2}{|c|}{ EUA } \\
\hline & $\begin{array}{c}\text { Estrutura } \\
\text { P\&D } \\
(2007)\end{array}$ & $\begin{array}{c}\text { Intensidade } \\
\text { PO em P\&D } \\
(2008)\end{array}$ & $\begin{array}{c}\text { Estrutura } \\
\text { P\&D } \\
(2014)\end{array}$ & $\begin{array}{c}\text { Intensidade } \\
\text { PO em P\&D } \\
(2014)\end{array}$ & $\begin{array}{c}\text { Estrutura } \\
\text { P\&D } \\
(2009)\end{array}$ & $\begin{array}{l}\text { Intensidade } \\
\text { PO em P\&D }\end{array}$ \\
\hline Alta & 31,42 & 15,76 & 37,06 & 26,80 & 74,25 & nd \\
\hline Média-alta & 60,12 & 5,56 & 50,43 & 9,98 & 16,68 & nd \\
\hline Média-baixa & 5,97 & 1,18 & 8,09 & 3,09 & 3,65 & nd \\
\hline Baixa & 2,48 & 0,55 & 4,41 & 1,54 & 5,43 & nd \\
\hline Total da Manufatura & 100,00 & 4,05 & 100,00 & 7,41 & 100,00 & nd \\
\hline \multicolumn{7}{|l|}{ Países em Desenvolvimento } \\
\hline & \multicolumn{2}{|c|}{ México } & \multicolumn{2}{|c|}{ China } & \multicolumn{2}{|c|}{ Brasil } \\
\hline Grupo de Setores OCDE & $\begin{array}{c}\text { Estrutura } \\
\text { P\&D } \\
(2009) \\
\end{array}$ & $\begin{array}{c}\text { Intensidade } \\
\text { PO em P\&D } \\
(2009) \\
\end{array}$ & $\begin{array}{c}\text { Estrutura } \\
\text { P\&D } \\
(2014) \\
\end{array}$ & $\begin{array}{c}\text { Intensidade } \\
\text { PO em P\&D } \\
(\mathbf{2 0 1 0})\end{array}$ & $\begin{array}{c}\text { Estrutura } \\
\text { P\&D } \\
(2014) \\
\end{array}$ & $\begin{array}{c}\text { Intensidade } \\
\text { PO em P\&D } \\
(\mathbf{2 0 1 0}) \\
\end{array}$ \\
\hline Alta & 13,11 & 1,70 & 21,98 & 4,74 & 9,08 & 9,67 \\
\hline Média-alta & 50,71 & 0,24 & 46,38 & 2,15 & 37,76 & 2,25 \\
\hline Média-baixa & 17,24 & 0,11 & 20,32 & 1,23 & 24,84 & 1,64 \\
\hline Baixa & 18,95 & 0,07 & 11,32 & 0,53 & 28,32 & 0,85 \\
\hline Total da Manufatura & 100,00 & $\mathbf{0 , 1 6}$ & 100,00 & 1,66 & 100,00 & $\mathbf{1 , 5 7}$ \\
\hline
\end{tabular}

Nota: nd - dados não disponíveis.

Fonte: elaboração própria com base nos dados da RAIS (MTE), PINTEC (IBGE), UNIDO e OCDE.

O Brasil mantém-se com níveis relativamentes estáveis de gastos com P\&D em proporção do PIB, cujo resultado em 2012 foi cerca de 1,15\%. Observou-se que todos os países apresentaram concentração dos gastos em P\&D em setores de média-alta tecnologia, com exceção dos EUA, que apresentaram maior concentração em setores de alta tecnologia. Os países em desenvolvimento, em geral, apresentaram participações em setores de média-baixa e baixa intensidade tecnológica superiores à de países desenvolvidos. De maneira geral, os esforços tecnológicos desses países, mensurados por meio da intensidade de recursos humanos, mostram-se abaixo de países tecnologicamente desenvolvidos, como Japão e Alemanha.

$\mathrm{O}$ posicionamento da intensidade dos gastos em $\mathrm{P} \& \mathrm{D}$ brasileiros face aos países selecionados sugere um atraso também no nível tecnológico (associado, obviamente, ao gap de produtividade). Nesse sentido, os esforços tecnológicos não auxiliam a reversão do movimento relativamente generalizado de falling behind apresentado pela indústria brasileira. Em comparação, a indústria chinesa ampliou seus esforços tecnológicos, enquanto que a brasileira se manteve estável. 
Dessa forma, o processo de mudança estrutural não tem auxiliado a indústria brasileira a avançar em direção à fronteira tecnológica internacional, ao passo que a indústria chinesa avança tecnologicamente, além de diminuir o gap de produtividade em relação à fronteira em todos os setores. O atraso tecnológico de Brasil e México sinalizam uma preocupação para o crescimento econômico desses países, visto que o fenômeno de mudança tecnológica parece ser um fator que não tem contribuído para um aumento de produtividade.

\section{Considerações finais}

Este trabalho procurou analisar as transformações na estrutura produtiva brasileira entre 2000 e 2014 em perspectiva comparada às transformações nas estruturas de Estados Unidos, Alemanha, Japão, China e México. Para tal, inicialmente buscou-se estabelecer um diálogo com a literatura nacional e internacional sobre o fenômeno da desindustrialização.

Como forma de contribuir a este debate, o artigo procurou compreender os determinantes deste fenômeno a partir de uma perspectiva mais ampla, que leve em consideração as transformações na lógica da concorrência, da organização e da acumulação na estrutura produtiva global. Ou seja, para além dos determinantes tradicionais do processo de desindustrialização nacional associados à crise do desenvolvimentismo e à vigência de preços macroeconômicos incompatíveis com a sustentabilidade do investimento industrial, o artigo enfatizou determinantes estruturais derivados da reconfiguração das cadeias globais e regionais de produção.

Dada a pervasividade dos impactos destas cadeias em diversas economias internacionais, procurou-se compreender em perspectiva comparada, como estes impactos estariam associados a diferentes padrões de transformações em economias com níveis de desenvolvimentos distintos de suas estruturas produtivas. Este esforço consolidou-se em duas dimensões. Primeiramente, analisou-se as transformações na principal indústria manufatureira mundial frente à consolidação das cadeias globais de valor. Em seguida, buscou-se mensurar como as estruturas produtivas das demais economias - com destaque para a brasileira - foram afetadas por esse movimento.

Paralelamente, o artigo analisou empiricamente como essas transformações afetaram o posicionamento relativo das economias frente à fronteira tecnológica internacional. De maneira geral, concluiu-se que, com exceção da China, todos os 
países apresentaram algumas características da vigência de um fenômeno de desindustrialização relativa. Adicionalmente, observou-se uma ampliação do diferencial de produtividade em relação aos EUA para todos os países analisados, novamente com exceção da China.

Como principal contribuição do trabalho cita-se a análise das transformações da estrutura produtiva brasileira a partir do arcabouço apresentado anteriormente e materializado em uma tipologia que combina:

(i) análise setorial da evolução do grau de distanciamento da indústria brasileira em relação à fronteira internacional segundo dois blocos de patamares de produtividade - setores com produtividade maior que a média e aqueles com produtividade menor que a média - e

(ii) segmentação setorial segundo níveis de dinamismo no mercado internacional.

Assim, foi possível qualificar os diferentes movimentos de distanciamento (falling behind) ou aproximação (catching up) segundo intensidade tecnológica em setores dinâmicos (com crescimento maior que a média mundial) ou não dinâmicos e setores com maior ou menor patamar de produtividade. Como conclusão, mostrou-se um fenômeno generalizado de aumento do gap de produtividade em relação à economia estadunidense, independentemente do nível de dinamismo dos setores bem como de seu patamar de produtividade, em aderência ao debate nacional sobre a tendência de desindustrialização precoce da economia brasileira.

\section{Referências}

AREND, M.; FONSECA, P. 25 anos de catching up, 25 anos de falling behind. Revista de Economia Política, v. 32, n. 126, p. 33-54, 2012.

AREND, M. A industrialização do Brasil ante a nova divisão internacional do trabalho. Texto para Discussão, Instituto de Pesquisa Econômica Aplicada (IPEA), 2015.

BALDWIN, R. Trade and industrialisation after globalisation's 2nd unbundling: how building and joining a sup.p.ly chain are different and why it matters. National Bureau of Economic Research, p. 1-38, 2011. 
BALDWIN, R.; LOPEZ-GONZALEZ, J. Sup.p.ly-chain trade: a portrait of global patterns and several testable hypotheses. The World Economy, v. 38, n. 11, p. 1682-1721, 2014.

CHANG, H.-J. Chutando a escada: a estratégia de desenvolvimento em perspectiva histórica, São Paulo: Editora Unesp, 2004.

CHANG, H.-J.; ANDREONI, A. Industrial policy in a changing world: basic principles, neglected issues and new challenges. Cambridge Journal of Economics, v. 40, n. 1, p. 1-52, 2016.

COHEN, W.; LEVINTHAL, D. Innovation and learning: the two faces of R\&D. The Economic Journal, v. 99, n. 397, p. 569-596, 1989.

DIEGUES, A.; ROSELINO, J. Indústria 4.0 e as redes globais de produção e inovação em serviços intensivos tecnologia: uma tipologia e apontamentos de política industrial e tecnológica. Texto para Discussão 356. Unicamp, 2019.

DIEGUES, A.; ROSSI, C. Além da desindustrialização: transformações no padrão de organização e acumulação da indústria em um cenário de "Doença Brasileira". Texto para Discussão 291. Unicamp, 2017.

DE BACKER, K.; DESNOYERS-JAMES, I.; MOUSSIEGT, L. Manufacturing or services - that is (not) the question. OECD Science, Technology and Industry Policy Papers, n. 19. OECD Publishing: Paris, 2015.

DOSI, G. Technological paradigms and technological trajectories: a suggested interpretation of the determinants and directions of technical change. Research Policy, v. 11, n. 3, p. 147-162, 1982.

ERNST, D.; KIM, L. Global production networks, knowledge diffusion, and local capability formation. Research Policy, n. 31, p. 1417-1429, 2002.

FREEMAN, C. The 'National System of Innovation' in historical perspective. Cambridge Journal of economics, v. 19, n. 1, p. 5-24, 1995.

FURTADO, C. Desenvolvimento e Subdesenvolvimento (1961). In: BIELSCHOWSKY, R. (Org.). Cinquenta anos de pensamento na CEPAL, vol. I. Rio de Janeiro: Record, 2000.

GEREFFI, G. International trade and industrial upgrading in the apparel commodity chain. Journal of International Economics, v. 48, n. 1, p. 37-70, 1999.

GEREFFI, G.; HUMPHREY, J; STURGEON, T. The governance of global value chains. Review of International Political Economy, v. 12, n. 1, p. 78-104, 2005. 
HIRATUKA, C.; SARTI, F. Transformações na estrutura produtiva global, desindustrialização e desenvolvimento industrial no Brasil. Revista de Economia Política, v. 37, n. 1, p. 189-207, 2017.

LANZ, R.; MAURER, A. Services and global value chains: some evidence on servicification of manufacturing and services networks. WTO Staff Working Paper, 2015.

LOS, B.; TIMMER, M.; DE VRIES, G. How global are global value chains? A new ap.p.roach to measure international fragmentation. Journal of Regional Science, 55 (2015): 66-92.

LUNDVALL, B. National Systems of Innovation: toward a theory of innovation and interactive learning. Londres: Pinter, 1992

MCMILLAN, M.; RODRIK, D. Globalization, structural change and productivity growth. National Bureau of Economic Research, p. 1-54, 2011.

MEDEIROS, C. A China como um duplo polo na economia mundial e a recentralização da economia asiática. Revista de Economia Política, v. 26, n. 3, p. 381-400, 2006.

MEDEIROS, C. Globalização e inserção internacional diferenciada na Ásia e América Latina. In: TAVARES, M. C.; FIORI, J. (Eds.). Poder e Dinheiro. Petrópolis: Vozes, 1997.

MELO, T.; CORREA, A.; CARVALHO, E.; POSSAS, M. Competitividade e gap tecnológico - uma análise comparativa entre Brasil e países europeus selecionados. Revista Brasileira de Inovação, v. 16, n. 1, p. 129-155, 2017.

MORCEIRO, P.; TESSARIN, M. Desenvolvimento industrial em perspectiva internacional comparada. Instituto de Estudos para o Desenvolvimento Industrial, 2019.

NOLAN, P. Is China buying the world? Challenge, v. 55, n. 2, p. 108-118, 2012.

NOLAN, P. Globalisation and industrial policy: the case of China. The World Economy, v. 37, n. 6, p. 747-764, 2014.

ORGANIZATION FOR ECONOMIC COOPERATION AND DEVELOPMENT - OECD. Structural Adjustment and Economic Performance. Paris: Organization for Economic Cooperation and Development, 1987.

PALMA, J. Quatro fontes de desindustrialização e um novo conceito de doença holandesa. In: Conferência de Industrialização, desindustrialização e 
desenvolvimento. São Paulo: Federação das Indústrias do Estado de São Paulo, 2005.

PEREZ, C. Revoluciones tecnológicas y capital financiero: la dinámica de las grandes burbujas financieras y las épocas de bonanza. México: Siglo XXI, 2004.

ROWTHORN, R.; WELLS, J. De-industrialisation and foreign trade. Cambridge: Cambridge University Press, 1987.

SARTI, F.; HIRATUKA, C. Desempenho recente da indústria brasileira no contexto de mudanças estruturais domésticas e globais. Texto para Discussão 290. Campinas: Unicamp, 2017.

STURGEON, T. Modular production networks: a new American model of industrial organization. Industrial and Corporate Change, v. 11, n. 3, p. 451- 496, 2002.

TREGENNA, F. Characterising deindustrialisation: an analysis of changes in manufacturing employment and output internationally. Cambridge Journal of Economics, v. 33, n. 3, p. 433-466, 2008.

VAN ARK, B.; O'MAHONEY, M.; TIMMER, M. The productivity gap between Europe and the United States: trends and causes. Journal of Economic Perspectives, v. 22, n. 1, p. 25-44, 2008.

\section{Agradecimentos}

Agradecimentos a CAPES pelo apoio financeiro. 